\title{
Desafíos de la puesta en marcha de la Jurisdicción Especial para la Paz
}

\begin{abstract}
Magda Stella Reyes Reyes ${ }^{1^{*}}$
Recepción: 02/04/2018 • Aprobación:28/09/2018 • Publicación: 19/12/2018

\section{Resumen}

La aplicación de la Justicia Transicional en Colombia basada en los diálogos y en el acuerdo de paz, desarrolla elementos importantes en relación a la ética del conflicto, la solución negociada y el reconocimiento de las víctimas. Estas herramientas razonables, enmarcadas con sigilo por los distintos protagonistas, como la creación de la Unidad de Búsqueda de Personas Desaparecidas, la Comisión de la Verdad y el Tribunal Especial para la Paz, ha logrado que una iniciativa del Gobierno colombiano y las FARC-EP, obtenga el mejor acuerdo posible, con legitimación democrática y un intento de lograr una paz estable y duradera (Reyes Alvarado, 2018).

Este año 2017 el desarrollo legal del acuerdo de paz ha esquematizado diversos actos legislativos, múltiples leyes y decretos reglamentarios al interior del sistema judicial colombiano. Existen problemáticas derivadas de las interpretaciones normativas desde el procedimiento y la prueba que se desarrolló de manera transversal en la Jurisdicción Especial para la Paz (JEP) con el condicionante del reconocimiento de la verdad y la responsabilidad (artículo transitorio inciso 5 del Acto Legislativo n. ${ }^{\circ} 001$ de 2017).
\end{abstract}

\footnotetext{
*Doctora en Derecho Penal y Procesal de la Universidad de Sevilla, España. Máster Universitario de Especialización en Derecho Penal, Instituto de Criminología de la Universidad de Sevilla. Diploma de Suficiencia I nvestigadora, p eriodo d e f ormación e i nvestigación, U niversidad d e $\mathrm{S}$ evilla. E specialista en Derecho Penal, Ciencias Criminológicas y Derecho Administrativo de la Universidad Externado de Colombia. Abogada, Universidad Santo Tomás de Bogotá Colombia. Ha sido directora del Centro de Conciliación y Arbitraje de la Facultad de Derecho de la Universidad La Gran Colombia, coordinadora jurídica del área de licitaciones y concursos públicos de la misma Universidad, así como Representante legal suplente jurídica del vicerrector administrativo. También se ha desempeñado como asistente de fiscal, fiscal delegada ante los Jueces Penales Municipales y del Circuito en Bogotá y en Ibagué, Tolima, Colombia. Ha sido docente universitaria de pregrado y posgrado y abogada litigante. Cuenta con diversas publicaciones en temas vinculados con el Derecho Penal, la Justicia Transicional, entre otros.
}

\section{Para citar este artículo}

Reyes Reyes, M. (2018). Desafíos de la puesta en marcha de la Jurisdicción Especial para la Paz. Dos mil tres mil, 20(1), 87-107. doi: https://doi.org/10.35707/dostresmil/20104 
Hasta la responsabilidad por la cadena de mando como referente jurídico de impacto en la política criminal y el proceso penal, siendo indispensable realizar una delimitación y análisis de cada caso en concreto, para evitar las persecuciones oportunistas. Este artículo busca desarrollar la conceptualización de estos contenidos y su análisis a la hora de ser puestos de presente en la práctica judicial.

Palabras claves: Justicia, Derecho, transicional, penal, víctimas.

\begin{abstract}
The application of Transitional Justice in Colombia based on the dialogues and peace agreement, develops important elements in relation to the ethics of the conflict, the negotiated solution and the recognition of the victims. These reasonable tools, stealthily framed by the different actors, such as the creation of the Search Unit for Missing Persons, the truth commission and the Special Court for Peace, have led to an initiative of a right-wing government that negotiated with a group of the left, get the best possible agreement, with democratic legitimacy and an attempt to achieve a stable and lasting peace. This year 2017 the legal development of the peace agreement has outlined various legislative acts, multiple laws and regulatory decrees within the Colombian judicial system. There are problems arising from the normative interpretations from the procedure and the test that was developed in a transversal way in the Special Jurisdiction for Peace (JEP) with the condition of the recognition of truth and responsibility (transitory article, paragraph 5 of the legislative act $\mathrm{N}^{\circ} 001$ of 2017).

Even the responsibility for the chain of command as a legal reference of impact on criminal policy and the criminal process, being essential to make a delimitation and analysis of each case in particular, to avoid opportunistic persecution. This paper seeks to develop the conceptualization of these contents and their analysis at the time of being present in the judicial practice.
\end{abstract}

Keywords: Justice, Law, Transitional, Criminal, Victims. 


\section{Introducción}

En la actualidad, la aplicación de la Justicia Transicional en Colombia basada en los diálogos y el acuerdo de paz, suscritos el pasado 24 de agosto de 2016 en La Habana, Cuba, sometidos a votación popular por el Gobierno colombiano el pasado mes de octubre de 2016 y finalmente concretados para su materialización en marzo de 2017, desarrolla elementos importantes en relación con la ética del conflicto, la solución negociada, reconocimiento de las víctimas directas afectadas por las atrocidades realizadas por los victimarios, los distintos niveles de victimización y los efectos indirectos generados por la guerra degradada por décadas.

Todas estas alternativas hicieron acortar el dolor y el sufrimiento asociados a la violencia e intentaron consolidar una legitimación de la democracia bajo una variada discusión política y una visibilidad de las víctimas en la exigencia de sus derechos.

En este desarrollo debemos entender la Justicia Transicional como la variedad de procesos y mecanismos asociados con los intentos de una sociedad por resolver los problemas derivados de un pasado de abusos a gran escala, a fin de que los responsables rindan cuentas de sus actos, sirvan a la justicia y logren una reconciliación (Walzer, 2004); tales componentes pueden ser judiciales o extrajudiciales y tener distintos niveles de participación nacional e internacional, incluyendo el enjuiciamiento de personas, el resarcimiento, la búsqueda de la verdad, la reforma institucional, la reparación colectiva e individual y las garantías de no repetición.

Los procesos de justicia transicional "se encuentran regulados por transformaciones radicales de orden social y político, aplicando el equilibrio de las exigencias contrapuestas de verdad, justicia y paz" (Uprimny Yepes, 2006, p.29). De la misma forma, los elementos que la conforman son los pilares principales en la búsqueda, recuperación y reconstrucción de los países en la etapa de posconflicto.

Personalmente, concibo la Justicia Transicional como un periodo de cambio transitorio que forma una institución jurídica y social e integra 
diversos esfuerzos en las sociedades que han sufrido algún periodo de violencia, discriminación, violación de Derechos Humanos e imposición de atrocidades, a fin salir de tal posición para lograr dentro de sus objetivos la construcción de la paz, reconciliación, armonía, bienestar social y consolidación de la democracia.

Para lograr la materialización de este concepto, se debe direccionar su actuar en los pilares fundamentales que la han concebido como principios o derechos (verdad, justicia, reparación y garantía de no repetición) que envuelve la transición y adquieren importancia porque emergen como límites que deben considerarse en las propuestas políticas de los gobernantes de turno. La garantía de los mismos y la manera cómo se conformarán las experiencias de la memoria histórica, las comisiones de la verdad, la aplicación de programas de reparación integral para las víctimas y el diseño de modelos de justicia, serán los eslabones que construirán la escalera de la paz.

Es por lo anterior que la creación de una estabilidad institucional, busca obtener la solución a los hechos combativos con matices de verdad, justicia, reparación y garantía de no repetición. En aras de lograr una reconciliación entre víctimas y victimarios a fin de reducir las brechas de desigualdad social en los contextos económicos y sociales (Regalado de Hurtado, 2007).

Dentro de este contexto se hace necesario direccionar nuestras ideas en la distinción de dos de los principios que envuelven la transición, partiendo de "la verdad como aquel conocimiento de las circunstancias de tiempo, modo y lugar de la ocurrencia de los hechos, a partir de la existencia real de los acontecimientos suscitados en el marco del conflicto armado colombiano" (Barreto Ardila, 2009, p.19).

Y la justicia en los procesos transicionales puede ser concebida como la construcción y el fortalecimiento de los escenarios que esclarecen la verdad a partir de las distintas formas de reparación, armonizando las peticiones de las víctimas y la declaratoria de responsabilidad de los agresores, a través de una investigación exhaustiva, oportuna y eficaz en la que se identifican los 
hechos, crímenes cometidos, consecuencias sociales y una posible estabilidad en el contexto social (Walzer, 2004).

En este artículo se desarrollará un primer enfoque basado en el derecho a la verdad a partir de su definición, características, clasificación y consecuencias de su aplicación en el contexto de la Jurisdicción Especial para la Paz como forma de materializar la Justicia Transicional en Colombia.

Un segundo referente es el derecho a la Justicia desde su noción, impacto y ejecución de las amnistías y la responsabilidad de mando como sinónimo de impunidad de un país acostumbrado a la lenta y ausente administración de justicia.

El ejercicio de estos derechos al interior de la Jurisdicción Especial para la Paz buscará su armonía en las soluciones jurídicas acertadas, utilizando la experiencia, el conocimiento y la contextualización de los principios que rodean la verdad, justicia, reparación y garantías de no repetición en aras de satisfacer cabalmente los derechos de las víctimas y la paz estable y duradera.

\section{Contenido}

En el año 2017, se realizó un desarrollo legal del acuerdo de paz esquematizado en diversos actos legislativos, múltiples leyes y decretos reglamentarios que han permitido una revisión del sistema judicial colombiano. En este contexto han existido problemáticas derivadas de las distintas interpretaciones normativas, sintetizadas en varios tópicos.

El primero se concibe desde la perspectiva del derecho a la verdad de manera individual como: "El derecho a saber de las víctimas y de sus familiares, acerca de las circunstancias en que se cometieron las violaciones" (Bonet Pérez, 2009, p.44). Para ello, la Corte Interamericana de Derechos Humanos ha establecido su carácter individual a:

El derecho a la verdad tiene, en esencia, una virtualidad reparadora, en la medida en que surge del deber del Estado de esclarecer los hechos relacionados con toda vulneración de los Derechos Humanos y de juzgar y castigar a los 
responsables (artículos 8 y 25 de la Convención Americana sobre Derechos Humanos. Corte Interamericana de Derechos Humanos, 2000, párrafo 201 / Corte Interamericana de Derechos Humanos, 2004, párrafo 31).

De la misma forma es la incapacidad de lidiar con lo ocurrido, siendo el origen del daño que padecen las víctimas, el guardar secretos dolorosos que pueden producir la parálisis de la capacidad de amar y actuar de las personas; es por lo anterior que los afectados al tener la posibilidad de contar su versión de los hechos generan empatías con su sufrimiento, respeto como personas, trato con dignidad, que no suelen ocurrir cuando dichas manifestaciones públicas no se han producido (Orentlicher, 2004).

A nivel colectivo es: "El derecho inalienable de toda sociedad, pueblo o comunidad a conocer los acontecimientos, circunstancias y motivos que llevaron a perpetración de los crímenes aberrantes sucedidos" (Gaviria Betancur, 2005, p.48). Este concepto engloba tanto el deber de conocer, como el deber de no olvidar, las causas que ocasionaron la vulneración de los derechos en la sociedad a fin de evitar que las mismas se repitan, mediante una reconstrucción de los hechos que incluyan los testimonios de los directamente afectados y se contribuya con los regentes memorísticos de lo sucedido (Botero \& Restrepo, 2006).

Para alcanzar este fin, el Estado se comprometerá en la creación e implementación de medidas tendientes a preservar la memoria colectiva, siendo esta, los recuerdos compartidos, trasmitidos y construidos que constituyen el esfuerzo irremediable de los grupos humanos para vincular el pasado con la realidad (Sánchez Gómez, 2012).

Dentro de estos contextos podemos sintetizar que el conocimiento de la verdad sirve para narrar la experiencia trágica y singular dando cuenta de quienes fueron las víctimas, honrando su dignidad e historia. El testimonio de los victimarios orientará los hallazgos y la verificación de los hechos, determinando patrones de sentido, desde lo dicho y lo no manifestado para enriquecer la narración. 
Se hace necesario que esta verdad ampliamente conocida y exigida por las víctimas, en el marco de su configuración integra, completa y pública, abarque la identidad de quienes participaron en el conflicto, beneficiando con este conocimiento a la sociedad civil, ya que permite el análisis y valoración de los contextos donde ocurrieron los episodios violentos que se pretenden superar (Orentlicher, 2004).

En los procesos de transición, el derecho a la verdad pondrá en marcha las estrategias y medidas eficaces, que permitan a las víctimas y a la sociedad conocer los acontecimientos del pasado, mediante la inclusión de sus protagonistas a fin de guiar el horizonte en la reconstrucción de la paz y la reconciliación por medio de la objetividad de los organismos de decisión política en el ejercicio de la democracia y pacificación de la sociedad (Joinet, 1997).

Por todo lo anterior, un primer componente relacionado con el procedimiento y la prueba que se desarrolló de manera transversal en la Jurisdicción Especial para la Paz (JEP), es el condicionante del reconocimiento de la verdad y la responsabilidad (artículo transitorio, inciso 5 del Acto Legislativo $\mathrm{n}^{\circ} 001$ de 2017).

La verdad, es concebida como principio del sistema de justicia integral de verdad, justicia, reparación y no repetición, siendo un presupuesto determinante en el acceso al tratamiento especial en la Jurisdicción Especial para la Paz (JEP) y el delineamiento de la idea de justicia, al ser carga compensatoria de las sanciones intramurales.

Se hace necesaria una verdad completa proveniente de los victimarios, siendo indispensable en su materialización con el trabajo arduo, juicioso y concentrado de la sala de reconocimiento de la verdad y responsabilidad encargada de corroborar dichos presupuestos.

Esta sala en la actualidad presenta una competencia insuficiente, porque a la hora de contribuir con este componente requiere de una institucionalización sólida que examine los posibles axiomas en la orientación, descubrimiento 
de las circunstancias de tiempo, modo y lugar en que ocurrieron los hechos y análisis empírico en contexto de casos, a fin de establecer verdades que no se constituyan en apotegmas dominables por intereses políticos e individuales.

Es indispensable en la búsqueda de este objetivo (verdad), que se establezca un conocimiento de los principales mecanismos que sirvan de referente en el proceso penal con la incorporación de los criterios de selección y priorización de casos considerados como la primacía en materia de investigación de hechos macrocriminales a partir de experiencias pasadas (Ley de Justicia y Paz).

Estas estrategias globales de investigación junto a la valoración unificada y contextualizada de procesos con varios victimarios pueden, en principio en el papel, asegurar una participación eficaz de las víctimas por medio de procedimientos ágiles con la aplicación de análisis en contextos, criterios de máximos responsables y caracterización de causas graves y representativas.

La importancia de la verdad radica en creer en el relato que realizarán los responsables; para esto, la víctima como centro de la Jurisdicción Especial para la Paz, se hará importante en el reconocimiento de sus derechos, siendo la verdad uno de ellos, ya que será una especie de espejo que relate lo sucedido en Colombia. Dentro de este contexto, se hace indispensable que los protagonistas de la Justicia Transicional (víctimas, victimarios y sociedad civil), realicen un duelo con el objeto de cicatrizar las heridas, a fin de restablecer sus lazos sociales, la convivencia pacífica, las relaciones interpersonales y la democracia.

Dentro de este hilo conductor, las víctimas en el conocimiento y recuento de la verdad, pueden contrastar los testimonios de los victimarios y si este último expresa verdades a medias o mentiras confundiendo a la autoridad o atribuyendo responsabilidades dispersas sin aterrizar la realidad, tendrá una serie de mecanismos que controlen estas dicotomías presentadas.

$\mathrm{Su}$ sanción o castigo será la pérdida de los beneficios judiciales condicionales por la verdad con el aumento del rango de pago de pena privativa de la libertad mayor de 10 o 20 años por el solo hecho de incumplir 
la palabra, a fin de asumir las consecuencias de sus actuaciones falaces ante la Jurisdicción Especial.

Las sanciones serán propias, alternativas y ordinarias; las primeras son las que van de 5 a 8 años que tendrán una función restaurativa y reparadora del daño causado, impuesta a todas aquellas personas que aceptan venir a la Jurisdicción Especial para la Paz para reconocer una verdad plena y completa en la asunción de su propia responsabilidad; existirá en igual sentido una sanción de 2 a 5 años destinada aquellos que no hayan tenido una participación determinante en la comisión del delito (Santos Calderón, 2016).

Las sanciones comprenderán restricciones efectivas de libertades y derechos en determinados lugares que establezca la Jurisdicción Especial para la Paz; durante este tiempo de privación de la libertad se adelantarán actividades como sustitución de cultivos ilícitos, erradicación de minas antipersonas, construcción y reparación de infraestructuras de zonas rurales y urbanas.

No existirá una pena privativa de la libertad en establecimiento carcelario porque la lógica del proceso de Justicia Transicional es la aplicación de medidas especiales que contribuyan en la obtención de las garantías y presupuestos basados en la verdad, justicia, reparación y garantías de no repetición.

Las sanciones alternativas son para aquellos victimarios que reconociendo verdad lo hacen de manera tardía cuando ya se ha iniciado un proceso de orden adversarial, la pena será de ocho años y dependerá su tasación de la forma de participación del victimario en la conducta punible que se investiga, en este contexto, la sanción es de carácter retributivo con elementos de privación de la libertad (Santos Calderón, 2016).

Las ordinarias son para aquellos investigados que aceptando venir a la Jurisdicción, sin reconocimiento de verdad ni responsabilidad, sometidos a juicio con catálogo de penas privativas de la libertad de 15 a 20 años. 
La puesta en marcha de esta Jurisdicción (JEP), debe aprender y conocer las experiencias del pasado aplicadas en los pormenores de la Ley de Justicia y Paz. Allí existió una colaboración e intento de contar la verdad por un gran número exparamilitares que había cumplido una condena alternativa en diferentes establecimientos carcelarios nacionales, quienes posteriormente fueron beneficiados con libertades masivas, legitimándose con la creación de las bandas criminales emergentes en las grandes ciudades de Colombia (Rabasa \& Chalk, 2003).

Para esta fecha, se realizaron 400000 horas de testimonios en audiencias de versión libre, se reconocieron a 77000 víctimas en los distintos procesos en todo el país, se confesaron 43000 delitos y se exhumaron 4000 víctimas desaparecidas para que sus cuerpos fueran entregados a sus familiares y se acompañara en el dolor que generaba la ausencia (Sánchez Gómez, 2013).

Pese a lo anterior, en la actualidad no se ha podido identificar a los máximos responsables de este fenómeno, porque la mayoría de beneficiarios de la Ley fueron escogidos por el gobierno de turno para ser investigados, dejando maniatados a las autoridades jurisdiccionales en el esclarecimiento de los hechos, la obtención de penas ejemplarizantes y la sanción a los violadores masivos de los Derechos Humanos.

Una de las soluciones que se propuso para efectos de solucionar esta dicotomía, es la creación de mecanismos judiciales de justicia, basados en el establecimiento de criterios de priorización y selección de casos, suspensión de la ejecución de la sanción y renuncia a la persecución penal para hechos no seleccionados; atendiendo a ello, se promulgó el Acto Legislativo n. ${ }^{\circ} 01$ de 2012, por medio del cual se instituyen los instrumentos jurídicos de Justicia Transicional, creando un artículo transitorio en la Constitución Nacional, que se aplicara de manera excepcional a fin de llevar a cabo una terminación del conflicto (artículo 1, Acto Legislativo n. ${ }^{\circ} 01$ de 2012).

La priorización contendrá una técnica de gestión, una investigación penal que permita establecer un orden de atención entre los reclamos de las víctimas relacionados con la justicia; para ello, contará con un precepto 
geográfico, político, económico, histórico y social en el cual se ha perpetrado la acción por parte del victimario, conociendo las estrategias de organización delictiva, su dinámica, aspectos logísticos y de funcionamiento (Montealegre Lynett, 2015).

Estos contextos dentro del su marco de acción permitirán conocer la verdad de lo sucedido, evitar la repetición de los actos atroces, establecer la estructura de la organización a la que pertenecía el victimario, determinar en la mayoría de las ocasiones el grado de responsabilidad de los integrantes del grupo y de sus colaboradores.

Una de las justificaciones para adoptar la aplicación de dichos criterios, es el impacto externo e interno de las estrategias que generaron la violencia, el contexto y gravedad del hecho atroz cometido y la identificación de los máximos responsables. Es por esto que esta política centra sus objetivos inmediatos en lograr un tránsito efectivo hacia la paz o la democracia, protección de los derechos de las víctimas y la aplicación de la justicia por medio de mecanismos expeditos de investigación, enjuiciamiento y castigo (Ambos \& Zuluaga, 2014).

El segundo componente se enfoca en el principio de Justicia, que encuentra su inmersión en el conjunto de disposiciones jurídicas codificadas que permiten interactuar, autorizar o prohibir ciertos comportamientos grupales o individuales, a fin de lograr una convivencia pacífica entre un conglomerado de personas en una comunidad. Esta significancia tendrá en cuenta a la sociedad, la época en que la misma se desarrolle y sus fundamentos pueden servir para que las personas delimiten su querer, actuar o saber en el conocimiento de lo bueno, malo, justo o injusto (Pieper, 2003).

Su noción sustantiva, es determinada con la afirmación y regulación de las normas que engloban su contenido en una capacidad para lograr un mejor bienestar social, incluyendo un catálogo concreto de derechos y deberes que mantienen un equilibrio en los grupos sociales, individuos y familias en general, en el marco de una confianza cívica y aplicación del sistema judicial que permita solucionar los conflictos existentes (Hatzfeld, 2004). Por medio de esta interpretación: 
Se logrará la imposición de penas adecuadas, proporcionales y detalladas a los responsables, de acuerdo a la gravedad del delito, las circunstancias individuales y sociales del procesado, los atenuantes y agravantes, verificando el comportamiento y colaboración efectiva en la investigación, el proceso, la reconstrucción de los hechos y la reparación de las víctimas. (Cortés Rodas, 2006, p. 85)

La amnistía puede considerarse como una disposición complementaria que atenúe el estado de guerra interior o el conflicto interno, pero no debe ser un festín de privilegios impuestos a los perpetradores de tales comportamientos, ya que cada Estado que decida aplicar la Justicia Transicional en su territorio debe respetar y cumplir los tratados internacionales por ellos suscritos, evitando interpretaciones amañadas que convaliden medidas internas violatorias de los mismos (Subijana Zunzunegui, 2006).

Así mismo, cada país que conoce a cabalidad las herramientas jurídicas que enmarcan el camino por la Justicia Transicional, procurará de manera inicial la aplicación de una efectiva o alternativa sanción traducida en penas privativas de libertad a todos aquellos que hayan vulnerado con su comportamiento los Derechos Humanos o el Derecho Internacional Humanitario, a fin de no sobrepasar los límites de amnistías o indultos a través de la condonación y extinción de penas que finalmente ocasionaría desconfianza en la sociedad, desosiego en las víctimas y grandes niveles de impunidad (Uribe de Hincapié, 2006).

Los Estados solo pueden conceder amnistías e indultos por delitos políticos o delitos comunes conexos con estos, esta alianza debe implicar una relación estrecha y directa entre ambas clases de delitos y bajo ninguna circunstancia, los delitos comunes objeto de una amnistía pueden constituir delitos graves conforme al Derecho Internacional o graves violaciones de los Derechos Humanos (Uribe de Hincapié, 2006).

Es por ello que la Jurisdicción Especial para la Paz en Colombia concede las amnistías solo para los delitos políticos, pero queda en deuda 
la definición de delitos conexos al político porque en la actualidad no existe una delimitación de esta concesión en la normatividad colombiana. Para ello, lo que se busca es que la Jurisdicción Especial realice un análisis de los casos que lleguen a su conocimiento y pueda delimitar el campo de acción de dichas conexidades.

Bajo el mismo derrotero, se encuentra relacionada la responsabilidad por la cadena de mando, al ser un referente jurídico de impacto en la política criminal y el proceso penal, ya que el mismo establece las relaciones de mando y jerarquía al interior de un grupo armado y la comprensión de su actuar, con pautas de responsabilidad fijas orientadas hacia la persecución de estas personas como máximos responsables; para ello, se hace indispensable realizar una delimitación y análisis de cada caso en concreto, para evitar las persecuciones oportunistas.

Siendo importante dentro de este ámbito la investigación en un criterio ascendente que permita incluir no solo al que ha participado en una decisión importante en el delito, sino a todas aquellas personas que hayan manejado canales de responsabilidad superior o dominio de los aparatos organizados de poder (Sentencia C- 579 de 2013).

Es indispensable establecer un concepto de máximo responsable, relacionado con la doble imputación que implica todo el contexto de crimen internacional frente a un determinado tipo de conductas que investigan el hecho individual y colectivo; esta estrategia servirá para seleccionar a los destinatarios de las investigaciones y juicios penales; para ello, "el marco jurídico para la paz propone como iniciativa el juzgamiento obligatorio de los victimarios que cumplan esta característica y para aquellos que sean autores materiales de los comportamientos violentos" (Suárez \& Velasco, 2016, p.261).

Vale la pena, dentro de este hilo conductor, traer como referente internacional la condena de Alberto Fujimori, siendo la primera decisión judicial que acusa a un expresidente como autor mediato por dominio de la voluntad sobre aparatos organizados de poder (la conocida construcción 
teórica de Roxin), aplicando las categorías del Derecho Penal con tintes criminales, debido a la ejecución masiva y sistemática dentro de la configuración de delitos internacionales.

Para ello, la eliminación de los grupos subversivos era la tarea del Ejército y de los servicios de inteligencia, que bajo la supervisión del presidente se ocupa de la selección del objetivo, concretando la ejecución de sus operaciones en manos del grupo paramilitar Colina, que posteriormente fue responsable de los hechos atroces presentados en Barrios Altos y Cantuta (Maculan, 2012). En este caso en concreto realizado por el expresidente:

Se presentó el dominio funcional del hecho (masacres y ejecuciones a la población indígena) sobre el aparato de poder, traducido en las fuerzas militares, desplegada con mayor responsabilidad en aquellos que ocupaban la cúspide de la organización basada en estructuras jerárquicas y rígidas, mediante una ejecución de mando con la capacidad de impartir órdenes y asignar roles, en el marco de la perpetuación de conductas criminales sistemáticas y su correspondencia en la comisión de dichos comportamientos punibles en nombre de la organización a la que pertenecían (Ambos, 2011, p.2).

En cuanto a la ejecución de la condena impuesta por el máximo Tribunal de la Justicia del Perú a Fujimori, se observó un proceso de limbo jurídico en las extradiciones solicitadas de manera inicial al Japón, que protegía su dignidad e integridad y posteriormente a Chile, que al principio rehusó la solicitud incoada por el Estado peruano para esta época.

Finalmente, se materializó la sentencia a 25 años de cárcel por los delitos de homicidio calificado, lesiones graves y secuestro agravado, siendo el primer antecedente judicial en el ámbito mundial de juzgamiento de un expresidente por crímenes en los que se vulneraron ostensiblemente los Derechos Humanos.

Bajo este derrotero, la Sentencia C-579 de 2013 dela Corte Constitucional estableció una definición confusa del término de máximo responsable, al no 
definir concretamente su campo de acción o delimitación de su aplicación en situaciones indeterminadas.

Dentro de este concepto se encuentran las personas con mayor jerarquía o poder de mando y los jefes máximos de la organización o institución, siendo estos el secretariado del grupo guerrillero por hechos como el uso de minas antipersonas que constituyen una de las estrategias de guerra para alejar o masacrar al enemigo. Así mismo, los mandos medios que participaron en actividades de homicidio o porte de armas o secuestros en contra de civiles inocentes (Cote Barco \& Tarapués Sandino, 2014).

Para mi criterio y acogiendo una interpretación del concepto de máximos responsables, sería el mayor número de casos que deben ser investigados por la Jurisdicción Especial para la Paz, ya que la definición de máximos responsables constituiría el cumplimiento de un papel esencial sin ser necesario delimitarlo al jefe del grupo o bloque.

Estos componentes meramente referidos, sumados a las amnistías, los indultos, la participación de las víctimas, la reincorporación de los combatientes y las distintas alternatividades al Derecho Penal son desenlaces derivados del intento en terminar el conflicto armado, que al no contar con un manejo adecuado, claro, coherente y articulado ocasionarían vacíos jurídicos en un segundo intento de aplicación de los pormenores parciales que abarcan la Justicia Transicional en Colombia.

Siendo importante que las sentencias que van a empezar a estructurarse en la Jurisdicción Especial para la Paz se basen en la verdad de las víctimas reconocida por los victimarios mediante una exposición detallada de los delitos ejecutados, para efectos de lograr una aplicación restrictiva de la libertad en cumplimiento a los mecanismos de reparación y restauración de los más afectados (De Roux, 2018).

En cuanto a los máximos responsables, se espera un enfoque y análisis detallado en cada caso en concreto que conduzca al direccionamiento de responsabilidades y obtención de justicia, a fin de superar el miedo de impunidad que enmarca la memoria de la mayoría de los colombianos. 
En este mismo contexto, vemos que el campo de acción de la Jurisdicción Especial para la Paz, no se basa en el castigo o pérdida de libertad del victimario en un establecimiento carcelario. Lo que se busca es la restauración de los derechos de las víctimas, la búsqueda y articulación de una estructura proactiva en la que todos los protagonistas de la Justicia Transicional direccionen el timón en la obtención de la paz y en el cambio de las ideologías de guerra y la ausencia de impunidad.

Dentro de este mismo derrotero, se hace importante la función que va a desempeñar la Comisión de la Verdad, establecida en el acuerdo de paz:

Como forma de obtención de una verdad humana, que no condena a nadie, que observa una explicación total de los posibles hechos atroces, las intenciones y responsabilidades para conseguir un encuentro interior de lo que somos como personas mediante la serenidad de los corazones de las víctimas y la oscuridad de los victimarios. (De Roux, 2018, p.196)

Precisamente, esta institución extrajudicial buscará una movilización nacional que recoja el sufrimiento, la indignación de las víctimas, para saber a ciencia cierta lo que pasó, con responsabilidades morales, sociales, en la obtención de una reconciliación nacional que cimiente un presente y observe un futuro con esperanza para toda Colombia.

Siendo importante considerar el posconflicto como una oportunidad excepcional de cambio social, cultural, político, económico, social y ambiental que nos ofrece la historia para corregir en forma pacífica los grandes defectos y fallas extremas que la sociedad colombiana acumula con el transcurrir del tiempo (Morales Nieto, 2015).

$\mathrm{Al}$ definir el posconflicto encontramos que no existe una respuesta única y dependerá su concepción de la percepción del ciudadano acerca de la violencia, la solución traducida en los acuerdos de paz firmados entre el Gobierno nacional y la guerrilla y la forma de percepción del futuro en el ejercicio de la democracia y la obtención de la paz. 
La razón de ser de estos planteamientos, es que los colombianos entendemos el legado nefasto y tenebroso que nos ha dejado la violencia sistemática y secular en nuestra mente, sistema de valores y comportamientos ciudadanos y se opte por una reconciliación y transición hacia la paz con la incursión de políticas sociales que ayuden a las víctimas en la consecución de un adecuado estado de bienestar.

En la actualidad, los diálogos de paz, el posterior acuerdo y su puesta en escena con la incursión de la Jurisdicción Especial para la Paz, ha hecho que elementos importantes como la ética del conflicto, la solución negociada, reconocimiento de las víctimas directas e indirectas afectadas por las atrocidades realizadas por los victimarios, los distintos niveles de victimización y los efectos generados por la guerra degradada por décadas, busquen acortar el dolor y el sufrimiento asociado a la violencia, consolidando una legitimación de la democracia, basada en una variada discusión política y una gran visibilidad de los más afectados en la exigencia de sus derechos.

Todo este análisis construye herramientas razonables enmarcadas con sigilo por los distintos protagonistas en la construcción de las causas del conflicto, su impacto, los efectos neutralizadores desde perspectivas comprensivas, finitas y limitadas.

Es por todo lo anterior que las víctimas, dentro de estos rumbos, constituyen el centro de atención, con la materialización de las políticas de desarrollo rural, el aumento y participación en entornos democráticos y la expresión de sus sentimientos ante estas iniciativas que enfrentaron los problemas estructurales ubicados en las raíces y dinamización del conflicto armado colombiano.

\section{Conclusiones}

En relación a la verdad, se hace importante la construcción de una memoria colectiva, que revise lo acontecido y aleje la ignominia en la que hemos vivido durante mucho tiempo. Para esto, se hace importante recordar y no olvidar el pasado en aras de permitir y promover acciones reivindicativas por parte de la sociedad y el Estado. 
Esta clase de Jurisdicción Especial le apuesta a una ideología de no impunidad, con el capítulo de sanciones que están establecidas en la normatividad y que busquen superar los odios que ha tenido la sociedad y la efectividad de los derechos de las víctimas con su reparación.

El derecho a la Justicia y los criterios de priorización y selección de casos constituirán instrumentos que enmarcan el contexto de la Justicia Transicional en Colombia, sin perjuicio del deber que tiene el Estado de investigar y sancionar las graves violaciones a los Derechos Humanos y el Derecho Internacional Humanitario; para ello, centrará sus esfuerzos en la investigación penal de los máximos responsables de todos los delitos que adquieran la connotación de crímenes de lesa humanidad, genocidio o crímenes de guerra cometidos de manera sistemática.

La Justicia Transicional y el elemento de justicia buscan un compromiso con la sociedad y el Estado colombiano en la adopción de las medidas que combatan la impunidad dentro del territorio colombiano; sin embargo, aquellas derivadas de una transición democrática hacia la paz pueden dar lugar al relajamiento de la obligación estatal de procesar y sancionar legalmente a quienes cometieron violaciones de los Derechos Humanos. Es por esto que figuras como la amnistía o el indulto constituyen opciones validas dentro de las negociaciones que se lleven a cabo con aquellos que quieran entablar un proceso de paz.

El Estado colombiano se encuentra en la obligación de investigar a todos y cada uno de los considerados máximos responsables, como aquellos victimarios que hayan dirigido o financiado la comisión de los delitos de lesa humanidad, genocidio y crímenes de guerra cometidos de manera sistemática; así como los que ordenaron la ejecución de los distintos delitos por medio de la materialización de conductas a través de las cuales se financie el narcotráfico.

Es en este contexto que la responsabilidad recaerá finalmente en el jefe máximo de la organización o sobre la persona con mayor jerarquía o poder (mandos medios) que dentro de su contexto participe de manera esencial en la ejecución y materialización de su comportamiento delictivo. 
Por lo anterior, el desafío de esta clase especial de Jurisdicción es precisamente el cuidado que deben tener sus magistrados y todo su grupo jurídico en las interpretaciones constitucionales y legales confusas que darán una mayor labor de análisis y detalle a la hora de delimitar el concepto de máximos responsables, bien como aquellas personas en las que recae la dirección o tenencia del control, a los determinadores o autores con criterios de dominio de hechos o situaciones analizadas a la luz de la dogmática penal.

Para finalizar, la estrategia de posconflicto busca curar un cuerpo social afectado por una enfermedad grave traducida en guerra, que requiere reconstrucción del tejido y de las heridas ocasionadas en el pasado. Para ello, el perdón, tratamiento de las víctimas y seguimiento de todas las instituciones, lograrán una efectiva armonización de la paz y democracia deseada durante años por la sociedad colombiana.

\section{Referencias}

Ambos, K. \& Zuluaga, J. (2014). Justicia de transición y constitución a manera de introducción, en Kai Ambos (coord.), Justicia de Transición y Constitución, análisis de la Sentencia C- 579 de 2013 de la Corte Constitucional. Bogotá, Colombia: Editorial Temis

Ambos, K. (2011). Sobre la "Organización” en el dominio de la organización, en Jesús María Silva Sánchez (dir.). Revista para el análisis del derecho (Indret). № 3, Barcelona, España, p.1-25. Recuperado de http://www.indret.com/pdf/839.pdf

Barreto Ardila, H. (2009). Las víctimas en el proceso de justicia y paz. Carácter simbólico de la verdad, la justicia y la reparación en la transición hacia la convivencia tolerante. En Memorias de las XXXI Jornadas Internacionales de Derecho Penal. Bogotá, Colombia: Universidad Externado de Colombia., p.17-36.

Bonet Pérez, J. (2009). La lucha contra la impunidad y sus implicaciones jurídicas internacionales para el ejercicio de la justicia transicional. En Jordi Bonet Pérez \& Rosa Ana Alija Fernández (edits.), Impunidad, Derechos Humanos y Justicia Transicional. Bilbao, España: Cuadernos de Deusto de Derechos Humanos. No 53, Universidad de Deusto, p.15-92. Recuperado de http://www.deusto-publicaciones. es/deusto/pdfs/cuadernosdcho/cuadernosdcho53.pdf

Botero Marino, C. (2005). Estándares internacionales y proceso de transición en Colombia. En Rettberg, A. (comp.), Entre el perdón y el paredón: Preguntas y respuestas de la justicia transicional. Bogotá, Colombia: Publicaciones del Centro Internacional para la Justicia Transicional / Universidad de los Andes, p. 45-108. Recuperado de https://www.minjusticia.gov.co/Portals/0/Foros\%20Justicia\%20 Transicional/LIBRO\%20J.TRANS..pdf 
Cortés Rodas, F. (2006). Entre el perdón y la justicia. Reflexiones en torno a los límites y contradicciones de la justicia transicional, en Camila De Gamboa Tapias (edit.), Justicia Transicional: Teoría y praxis. Bogotá, Colombia: Editorial Universidad del Rosario, p.85-112.

Cote Barco, G. E. \& Tarapués Sandino, D. F. (2014). El marco jurídico para la paz y el análisis estricto de sustitución de la Constitución realizado en la Sentencia C-579 de 2013. En Kai Ambos (coord.), Justicia de transición y constitución, análisis de la Sentencia C-579 de 2013 de la Corte Constitucional, Bogotá, Colombia: Editorial Temis, p.197-273.

De Roux, F. (2018). La audacia de la paz imperfecta. Bogotá, Colombia: Editorial Ariel. Gaviria Betancur, P. (2005). El derecho a la verdad. En Los derechos de las víctimas en los procesos de Justicia Transicional. Justicia, verdad y reparación. Bogotá, Colombia: Fundación Social, Asesoría de Derechos Humanos y Paz y Programa de Derechos Humanos de la Agencia de los Estados Unidos para el Desarrollo Internacional, p.41-63.

Hatzfeld, J. (2004). Una temporada de machetes. Barcelona, España: Editorial Anagrama. Joinet, L. (1997). Informe final revisado acerca de la cuestión de la impunidad de los autores de violaciones de los Derechos Humanos (Derechos Civiles y políticos). Resolución 1996/119 de la subcomisión, Comisión de Derechos Humanos, 49 periodos de sesiones. E/CN.4/Sub.2/1997/20/Rev.1, octubre 2 de 1997. Párrafo19, p.69104. Recuperado de http://www.coljuristas.org/documentos/libros_e_informes/ principios_sobre_impunidad_y_reparaciones.pdf.

Maculan, E. (2012). La respuesta de las graves violaciones de Derechos Humanos entre derecho penal e internacional. Observaciones sobre el caso de Fujimori. Revista Electrónica de Ciencia Penal y Criminología (RECPC), p.5-32. Recuperado de http://criminet.ugr.es/recpc/14/recpc14-05.pdf

Montealegre Lynett, E. (2015, agosto). Componentes básicos de la política de priorización. Cartilla Número 01.Bogotá: Colombia: Ediciones Fiscalía General de la Nación. Recuperado de https://www.fiscalia.gov.co/colombia/wp-content/uploads/CHP_ Cartilla1_AF_Digital.pdf

Montealegre Lynett, E. (2015, agosto). Priorización intra e interdependencias. Cartilla Número 02. Bogotá, Colombia: Ediciones Fiscalía General de la Nación. Recuperado de https://www.fiscalia.gov.co/colombia/wp-content/uploads/CHP_ Cartilla2_AF_Digital1.pdf

Morales Nieto, J. (2015) ¿Qué es el postconflicto? Colombia después de la guerra. Bogotá, Colombia: Ediciones B. Grupo Z.

Orentlicher, D. (2004). Estudio independiente con inclusión de recomendaciones, sobre las mejoras prácticas, para ayudar a los Estados a reforzar su capacidad nacional con miras a combatir todos los aspectos de la impunidad. Comisión de Derechos Humanos, E/CN.4/2004/88.27 de febrero de 2004, párrafo11, p.111142. Recuperado de http://www.coljuristas.org/documentos/libros_e_informes/ principios_sobre_impunidad_y_reparaciones.pdf

Pieper, J. (2003). Las virtudes fundamentales. Madrid, España: Ediciones Rialp.

Rabasa, A. \& Chalk, P. (2003). El laberinto colombiano: Propuestas para la resolución del conflicto. Bogotá, Colombia: Ediciones Universidad Externado de Colombia. 
Regalado de Hurtado, L. (2007). Estudios sobre historia, memoria y pasado reciente. Lima, Perú: Fondo Editorial de la Pontificia Universidad Católica del Perú-Universidad Nacional Mayor de San Marcos.

Reyes Alvarado, Y. (2018). Presentación. En Reyes Alvarado, Y. (edit.) ¿Es injusta la Justicia Transicional? Bogotá, Colombia: Centro de Investigación en Filosofía y Derecho, Universidad Externado de Colombia.

Sánchez Gómez, G. (2013). Memorias: La voz de los sobrevivientes, en Sánchez Gómez G. (coord.) ¡Basta ya! Colombia: Memorias de guerra y dignidad. Bogotá, Colombia: Informe General del Grupo de Memoria Histórica, Imprenta Nacional, p.328387. Recuperado de http://www.centrodememoriahistorica.gov.co/descargas/ informes2013/bastaYa/basta-ya-colombia-memorias-de-guerra-y-dignidad-2016. pdf

Sánchez Gómez, G. (2012). Justicia y paz. ¿Verdad judicial o Verdad histórica? Bogotá: Colombia: Taurus Pensamiento, Centro de Memoria Histórica \& Revista semana. Recuperado de http://centrodememoriahistorica.gov.co/descargas/informes2012/ verdad_judicial_verdad_historica.pdf

Santos Calderón, J. M. \& Jiménez, T. (2016). Acuerdo final para la terminación del conflicto y la construcción de una paz estable y duradera. Bogotá, Colombia. Recuperado de http://www.funcionpublica.gov.co/eva/gestornormativo/norma.php?i=79893

Sentencia C-579 (2013). Corte Constitucional de Colombia. Magistrado ponente: Jorge Ignacio Pretelt Chaljub.

Suárez, E. \& Velasco, E. (2016). Máximos responsables. En Bernal Pulido, C., Barbosa Castillo, G. \& Ciro Gómez, A. R. (edits.). Justicia Transicional: Verdad y responsabilidad. Vol. 4. Bogotá, Colombia: Ediciones Universidad Externado de Colombia, p. 173-273.

Subijana Zunzunegui, I. J. (2006). El principio de protección de las víctimas en el orden jurídico penal. Del olvido al reconocimiento. Granada, España: Comares.

Uprimny Yepes, R. (2006). Las enseñanzas del análisis comparado: Procesos transicionales, formas de Justicia Transicional y el caso colombiano. En Uprimny Yepes, R. (Ed.), ¿Justicia Transicional sin transición?, Verdad, justicia y reparación para Colombia. Bogotá, Colombia: Centro de Estudios de Derecho, Justicia y Sociedad, p.16-42. Recuperado de https://www.minjusticia.gov.co/Portals/0/Foros\%20Justicia\%20 Transicional/LIBRO\%20J.TRANS..pdf

Uribe De Hincapié, M. T. (2006). Esclarecimiento histórico y verdad jurídica: Notas introductorias sobre el uso de la verdad. En De Gamboa Tapias, C. (edit.), Justicia Transicional: Teoría y praxis, Bogotá, Colombia: Ediciones Universidad del Rosario, p.324-344.

Walzer, M. (2004). Reflexiones sobre la guerra. Barcelona, España: Ediciones Paidós. 